\title{
VITAMIN C AND UPPER RESPIRATORY ILLNESS IN NAVAHO CHILDREN: PRELIMINARY OBSERVATIONS (1974)
}

\author{
John L. Coulehan, * Louis Kapner, and Susan Eberhard \\ United States Public Health Service \\ Fort Defiance Indian Hospital \\ Fort Defiance, Arizona 86504
}

Floyd H. Taylor and Kenneth D. Rogers

Department of Community Medicine

University of Pittsburgh School of Medicine

Pittsburgh, Pennsylvania 15261

In a large double-blind study among Navaho school children, we evaluated the effects of vitamin $\mathrm{C}$ in 1- and 2-gram daily doses on acute respiratory illness during a 14-week period. ${ }^{1}$ We found no evidence of significant prophylaxis, but our findings did suggest a modest therapeutic benefit in that children taking vitamin C had from $28 \%$ to $34 \%$ fewer days of morbidity caused by respiratory episodes than those taking placebo. Likewise, in classroom surveillance, younger children on vitamin C had $26 \%$ fewer symptom-days of cough and nasal discharge recorded. These observations were consistent with other recent trials using 1 gram daily (4 grams during illness) in Canadian adults ${ }^{2}$ and 250-500 milligrams daily in Irish schoolchildren. ${ }^{3}$

The clinical significance of this modest therapeutic result in minor, selflimited illness was, in itself, questionable. However, further study was indicated to determine: (a) if use of vitamin $\mathrm{C}$ could prevent complications of the common cold in children, such as superinfections or otitis media; (b) if certain symptoms or symptom complexes responded specifically to vitamin $\mathrm{C}$ therapy; and (c) if indeed, as our data had suggested ${ }^{1}$ higher blood ascorbic acid levels were correlated with fewer days of illness. A second investigation was designed to confirm, if possible, and expand our previous findings. The second trial was conducted in two Navaho boarding schools during January through May 1974, using doses of 1 gram vitamin C daily versus placebo tablets. This report presents preliminary routine surveillance findings from the second study.

MATERIALS AND METHODS

Subjects

The study population included children enrolled at two Navaho elementary schools, Toyei Boarding School, located at Steamboat, Arizona, and Lower

* Present address: Department of Community Medicine, Scaife Hall, University of Pittsburgh School of Medicine, Pittsburgh, Pennsylvania 15261. 
Greasewood Boarding School, located at Greasewood, Arizona. There was an Indian Health Service clinic at each school and a physician, physician assistant, or registered nurse was available throughout each week at each location. Parental permission forms for participation in the study were obtained during the autumn of 1973. Permission to conduct the investigation was granted by the Indian Health Service, the Bureau of Indian Affairs, and appropriate Navaho tribal authorities.

There were 944 children with parental permission at the outset, with 484 at Greasewood and 460 at Toyei, representing approximately $80 \%$ of the total enrollment at both schools. These students ranged in age from 6 through 15 years, and all lived at school, with the exception of 83 day students at Greasewood. The schools had identical diets that were designed by a Public Health Service nutritionist, and which contained vitamin $\mathrm{C}$ in excess of recommended minimal daily requirements.

\section{Tablets and Procedures}

Tablets manufactured for this study contained 500 milligrams of ascorbic acid in anhydrous form, while placebo tablets were formulated from citric acid to be identical in appearance and taste to the ascorbic acid pills. This was different from our first clinical trial, in which the study tablets were composed of sodium ascorbate and ascorbic acid in a ratio of approximately 3:1. Each child received supplements from his own bottle, identified only by study number. Individual treatments were assigned randomly by computer within groups of 20 consecutive study numbers. Persons involved in data collection or tablet distribution had no access to treatment information, although the study coordinator (S.E.) retained a master key to use in case of adverse reactions.

The investigation was conducted from January through mid-May at Greasewood School, a period of 18 weeks, while at Toyei the study was 15 weeks in length. Children received two tablets daily (1 gram for those on vitamin C) from their personal supply, supervised by teachers at the beginning of each school day. On Fridays or before holidays, children received individual packets for use on the weekend or holiday period, but there was no close supervision outside the classroom and those who were absent from school unexpectedly did not receive treatments during their absence. Children were supposed to take the supplements whether they felt sick or well.

\section{Data Collection}

Three major types of observations were made during this study. The first was active surveillance conducted by a trained clerk at each school. The clerk rotated through all classrooms according to a fixed schedule, seeing each child once in a two-week period. Each student was asked individually if he or she were experiencing any of the following symptoms on that given day: nasal discharge, sneezing, coughing, earache, sore throat, aching all over, abdominal pain, diarrhea, vomiting, or skin sores. The child's answer was accepted and recorded without probing or examination, and only presence or absence of the symptom was indicated.

The second type of observation involved clinical episodes of illness, as 
defined in our previous report. ${ }^{1}$ Written diagnostic criteria were established for four respiratory syndromes (upper respiratory infection, pharyngitis, otitis media, and lower respiratory infection), and, in addition, other diagnostic categories included gastroenteritis, impetigo, conjunctivitis, injury, and all other illness. Each child was followed daily until all symptoms subsided. A third type of data was plasma ascorbic acid levels, determined at various hours after supplementation, and at different times during the course of the study, in children on both treatment regimens. The clinical episode and plasma ascorbic acid results will be the subject of a further report.

\section{RESULTS}

Of the original 944 children participating, $76(8 \%)$ dropped out during the course of the investigation. Twenty-one Greasewood students were eliminated because of high absentee rates amounting to greater than one-third of the total study days. Since accurate attendance records were unavailable for Toyei Boarding School, no children there could be dropped for high absenteeism. The remaining 55 officially left school, were unwilling to take their tablets in class, or were terminated from the program upon parental request No children left the study because of known adverse effects. This analysis includes the experience of 868 children who completed the entire study period.

Active surveillance was initiated during the second study week, and seven or eight circuits were completed to all classrooms during the balance of the study. Of 6,054 possible child-days of observation, there were 1121 absences, 590 (19.7\%) among children taking vitamin $\mathrm{C}$ (C children) and $531(17.3 \%)$ among those on placebo ( $\mathrm{P}$ children). These were primarily absences from school, although in some cases a child may have simply been out of the classroom at the given time. TABLE 1 illustrates absence percentages by age and sex and compares these to percentages found on classroom surveillance in our earlier trial at Toyei School alone. Overall percentage of absences was higher than previously, and C children were absent more often than P children in 1974, whereas the opposite occurred in 1973.

TABLE 2 shows the percentage of observation days positive for various symptoms at the two schools. The absolute incidence of affirmative responses was much greater at Greasewood than at Toyei, with symptoms noted an average of 3.1 times more frequently at Greasewood when all groups were considered. Consequently, results from the different schools were not combined in further analyses. Within each school, there were no consistent, meaningful differences between treatment groups noted for cold symptoms, including both catarrahal and more nonspecific symptom types. However, at Greasewood "side effect" symptoms (abdominal pain and diarrhea) were observed signicantly more often in $\mathrm{C}$ children, although the actual incidence of these complaints in any group was quite low. The "skin sores" symptom was introduced as a control category, since there was no reason to believe ascorbic acid supplements would influence skin sores in this adequately nourished population. $\mathrm{C}$ children, however, admitted to skin sores $45 \%$ more frequently than $\mathrm{P}$ children at Greasewood, and while there as a tendency toward the opposite distribution at Toyei, it was not a significant difference. This finding may suggest that $\mathrm{C}$ children at Greasewood constitute a group more prone to acknowledge symptoms than the $\mathrm{P}$ children, for reasons unrelated to treatment regimen. 


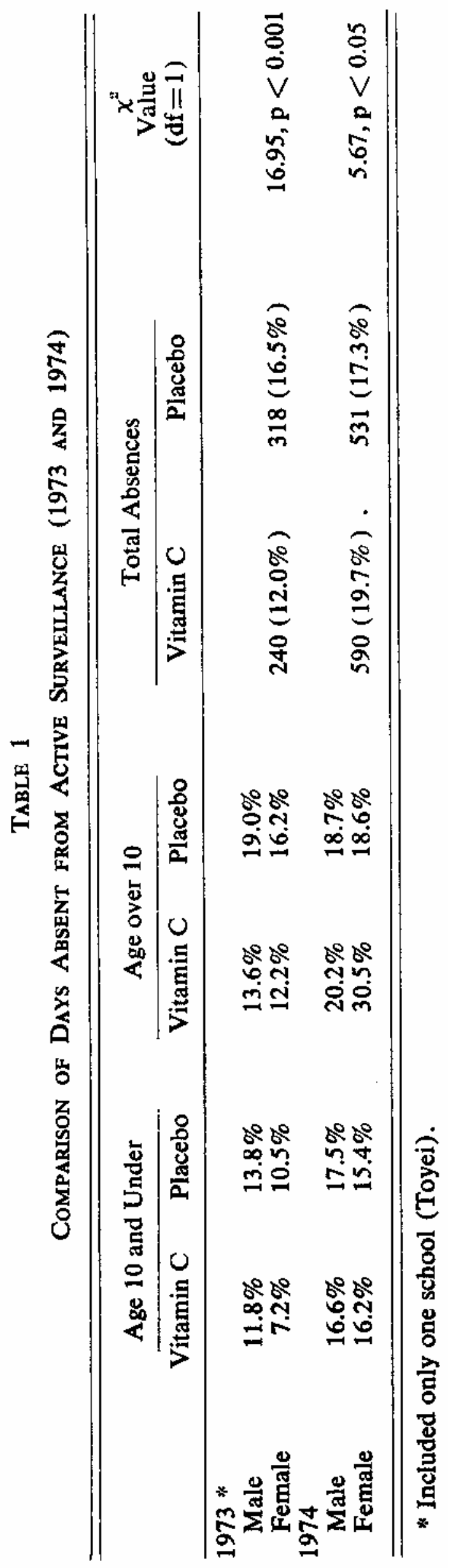


In TABLE 3 "sick days" include all child-days of observation in which one or more symptoms were present. There were significantly fewer sick days from cold symptoms found in younger children on vitamin $\mathrm{C}(-14 \%)$, but this difference was small and contrasted with more frequent sick days among older C children $(+21 \%)$, albeit the latter was not a significant difference. On the other hand, $38 \%$ more sick days including side-effect symptoms were seen in $\mathrm{C}$ children at Greasewood. Both individual symptoms and sick days were also analyzed by sex, by various ages, and by time periods within the study; no consistent patterns were found that would suggest a positive clinical effect of 1gram ascorbic acid supplements.

TABLE 2

OBSERVATION DAYS POSITIVE FOR INDIVIDUAL SYMPTOMS ON ACTIVE SURVEILLANCE

\begin{tabular}{lccccc}
\hline & \multicolumn{2}{c}{ Greasewood School } & & \multicolumn{2}{c}{ Toyei School } \\
\cline { 2 - 3 } \cline { 5 - 6 } \multicolumn{1}{c}{ Symptom } & Vitamin C & Placebo & & Vitamin C & Placebo \\
\hline Nasal discharge & $14.7 \%$ & $14.2 \%$ & & $4.8 \%$ & $6.0 \%$ \\
Sneezing & 9.2 & 9.0 & & 0.6 & 1.0 \\
Coughing & 23.2 & 24.1 & & 10.2 & 10.7 \\
Earache & 7.6 & 7.7 & & 2.1 & 1.1 \\
Sore throat & 12.8 & 10.3 & & 2.8 & 3.6 \\
Aching all over & 1.6 & 2.6 & & 3.9 & 4.1 \\
Abdominal pain & $5.3 *$ & $3.3 *$ & & 1.6 & 1.2 \\
Diarrhea & $4.4 \dagger$ & $2.3 \dagger$ & & 0.5 & 0.2 \\
Vomiting & 5.1 & 4.6 & & 0.2 & 0.2 \\
Skin sores & $13.6 \dagger$ & $9.4 \dagger$ & 2.6 & 3.4 \\
\hline \hline
\end{tabular}

* Number of symptom-days positive in $\mathbf{C}$ group significantly greater than in $\mathbf{P}$ group, $\chi^{2}=6.38, \mathrm{df}=1, \mathrm{p}<0.05$.

† Number of symptom-days positive in $\mathrm{C}$ group significantly greater than in $\mathbf{P}$ group, $\chi^{2}=9.09$ (diarrhea), $\chi^{2}=11.71$ (skin sores), $\mathrm{df}=1, \mathrm{p}<0.01$.

\section{DISCUSSION}

While Pauling has proposed that daily vitamin $\mathrm{C}$ in sufficient dosage can prevent most colds, ${ }^{4}$ recent double-blind trials have not shown such a prophylactic effect with doses ranging from 500 milligrams to 2 grams daily. ${ }^{1-3,5}$ Likewise, ascorbic acid in 1.5- and 3-gram supplements has failed to prevent colds induced by intranasal rhinovirus inoculation. ${ }^{6,7}$ On the other hand, evidence regarding a therapeutic effect of ascorbic acid on the common cold has been inconsistent. We observed fewer total days of morbidity in Navaho schoolchildren taking 1- and 2-gram supplements during illness as opposed to placebo. ${ }^{1}$ In routine surveillance, this reduction related primarily to catarrhal symptoms (cough, nasal discharge), which was consistent with observations made on Irish children by Wilson and Loh. ${ }^{3}$ However, while observing the course of illness episodes, we found the therapeutic effect quantitatively similar but less specific, involving nonrespiratory syndromes as well. The latter findings corre- 


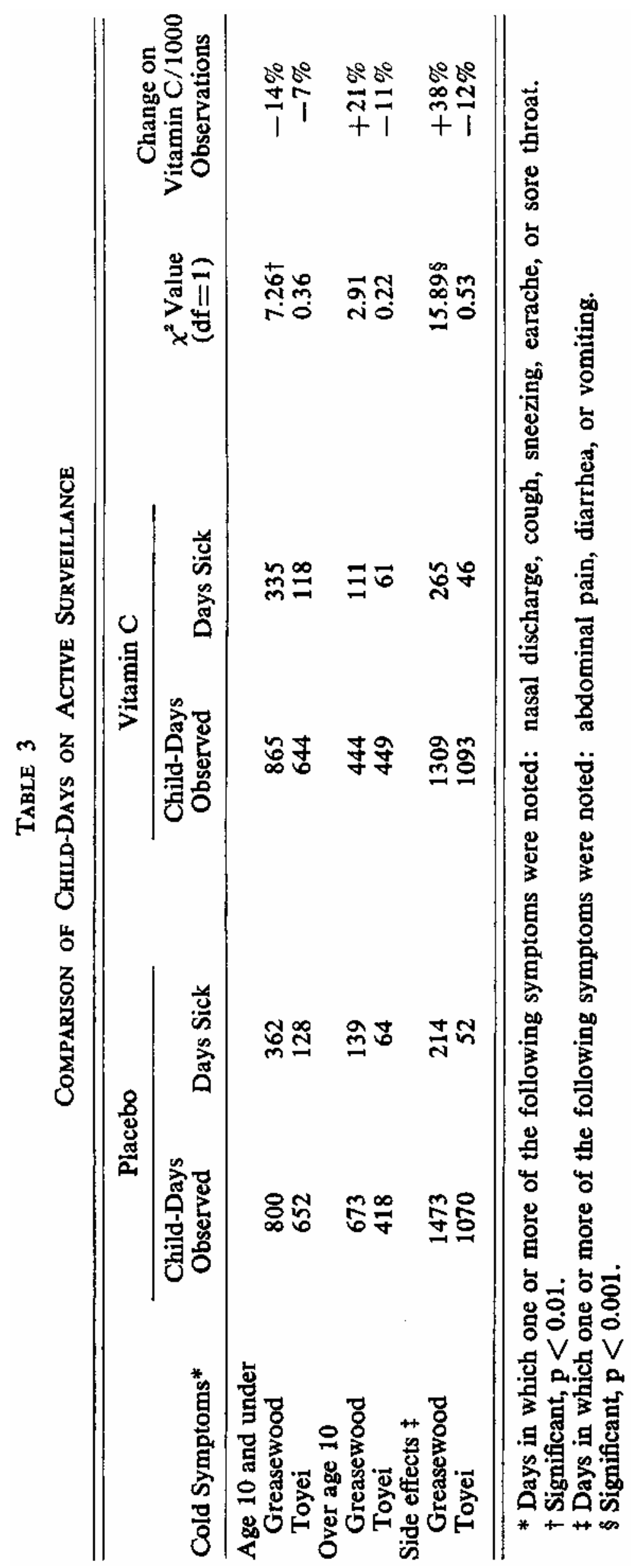


lated with those of Anderson et al., who noted $30 \%$ fewer days confined to home in adults taking 4 grams of vitamin $\mathrm{C}$ daily during illness, an effect that was most evident in syndromes with generalized, nonrespiratory symptoms. ${ }^{2}$ In a subsequent study, however, Anderson showed only minimal and not statistically significant therapeutic value of vitamin $C{ }^{5}$ He used a wide range of doses, up to 8 grams daily during the first four days of illness, and noted that the small ameliorative effect appeared to be dose-related.

Our hypotheses in the present study related to therapy rather than prophylaxis: specificity, value in secondary prevention, and relationship of plasma ascorbic acid levels to severity of symptoms. It was not practical, however, to give supplements only during illness in this population. Consequently, a 1-gram daily dose was given whether the child felt sick or well, and, in fact, supplementation during illness was less supervised that that during health if the child was sick enough to be absent from class. The surveillance method was used to detect primarily mild symptoms that caused neither absence nor referral to medical care. We found no meaningful differences in cold symptomatology between $\mathrm{C}$ and $\mathrm{P}$ children with this method, although younger children at Greasewood on C had 14\% fewer sick days noted. Earache, a symptom that could be related to a complication of colds (otitis media), was no less frequent among $\mathrm{C}$ children. On the other hand, those on $\mathrm{C}$ had significantly more side effects (diarrhea and abdominal discomfort) observed at Greasewood.

How can the discrepancies between these findings and our previous study ${ }^{x}$ be explained? The surveillance method on sequential classroom visitation was the same as used previously, and many of the same personnel were involved. However, there are two indications that the data obtained by this technique are "softer" than we had supposed. First, individual symptoms were recorded up to 9 times more frequently at one school than at the other in this trial, with an overall factor of about three regardless of treatment group. This can be explained only by significant differences in child-observer interactions at the two schools, and results cannot be considered additively. Moreover, such large variations that apparently result from interview technique shed some doubt on the meaningfulness of the $25-30 \%$ intergroup differences we reported earlier, albeit only from one school with basically one observer. ${ }^{1}$ Secondly, C children were more often absent from surveillance and more likely to acknowledge a neutral symptom (skin sores) than P children, at least at one school. In our first study, P children were more frequently absent (TABLE 1). These inconsistencies at least suggest that children in the two groups may by chance have differing characteristics, unrelated to treatment regimen; for example, the $\mathrm{C}$ population in this study may contain more children with a high index of responsiveness to questioning than the $\mathrm{P}$ population.

In any case, the conflicting results indicate that this method is not sensitive enough to delineate a pharmacological action of ascorbic acid in a dose of 1 gram daily, if indeed such an action does exist. We anticipate that analysis of biochemical data and the clinical episode data, reflecting actual "illness" rather than more evanescent "symptoms," may clarify the matter. A specific symptomatic benefit, for example, could explain the conflicting findings in various studies in that methodology, population, and the syndromes prevalent at the time of the study could all influence whether, and to what extent, benefit was observed in the given investigation. Nevertheless, this suggests that vitamin C is unlikely to have widespread usefulness as a cold remedy.

Some recent work is suggestive in proposing a site of action for ascorbic 
acid in cold therapy, and in demonstrating physiological changes in leukocyte ascorbic acid levels during upper respiratory illness. Valic and Zuskin ${ }^{9}$ and Zuskin et al. ${ }^{8}$ have shown that aerosols of ascorbic acid have a definite effect in preventing or ameliorating histamine-induced bronchospasm in humans and experimental animals. This effect was evident in pulmonary function studies on a group of flax workers, some of whom had bysinnosis. ${ }^{9}$ However, little is known about the functional aspects of acute airway responses during the common cold. It is clear, though, that a modest antihistaminic action could provide some relief for symptoms such as nasal congestion and cough, particularly in those persons with an allergic component to their cold syndrome.

Leukocyte ascorbic acid levels have been shown to decrease in response to colds, ${ }^{3,10}$ and to return to values near normal after about four days. Use of 1 to 6 grams of vitamin $\mathrm{C}$ daily during the illness can diminish or prevent this effect. ${ }^{10}$ However, a drop in leukocyte ascorbic acid may well be a nonspecific response to a variety of stresses, such as in the case of myocardial infarction. ${ }^{11}$ There is no substantial evidence that preventing this physiologic correlate of colds has any clinical consequences. Our earlier work did, however, indicate that children with higher whole-blood ascorbic acid levels had fewer observed days of illness on surveillance than those with lower ascorbic acid levels. ${ }^{1}$ This was based on a single blood specimen, drawn approximately 24 hours after the last supplement was given, and on a small number of observations, both in terms of children (67) and days sick (30 versus 55). Analysis of biochemical data from the present study should shed further light on this association.

\section{ACKNOWLEDGMENTS}

We are indebted to Hoffmann-La Roche, Inc., Nutley, New Jersey, for materials used in this study, and for additional funding. In particular, we wish to thank Myron Brin for his assistance and encouragement.

\section{REFERENCES}

1. COUlehan, J. L., K. S. REISINGER, K. D. ROGERS \& D. W. BRADLEY. 1974. Vitamin $C$ prophylaxis in a boarding school. New Eng. J. Med. 290: 6-10.

2. ANDERSON, T. W., D. B. W. REID \& G. H. BEATON. 1972. Vitamin C and the common cold: a double-blind trial. Can. Med. Ass. J. 107: 503-508.

3. WILSON, C. W. M. \& H. S. LOH. 1973. Common cold and vitamin C. Lancet 1: $638-641$.

4. Pauling, L. C. 1970. Vitamin C and the Common Cold. W. H. Freeman \& Company. San Francisco, Calif.

5. ANDERSON, TVW., G. SURANYI \& G. H. BEATON. 1974. The effect on winter illness of large doses of vitamin C. Can. Med. Ass. J. 111: 31-36.

6. SASAKI, Y., Y. TOGO, H. N. WAGNER, JR., R. B. HORNICK, A. R. SCHWARTZ \& D. F. PROCTER. 1973. Mucociliary function experimentally induced rhinovirus infection in man. Ann. Otol. 82(2) :203-211.

7. SCHWARTZ, A. R., Y. TOGO, R. B. HORNICK, S. TOMINAGA \& R. A. GLECKMAN. 1973. Evaluation of the efficacy of ascorbic acid in prophylaxis of induced rhinovirus 44 infection in man. J. Infect Dis. 128(4): 500-505.

8. ZUSKIN, E., A. J. LEWIS \& A. BOUHUYS. 1973. Inhibition of histamine-induced airway constriction by ascorbic acid. J. Allergy Clin. Immunol. 51: 218-226.

9. VALIC, F. \& E. ZUSKIN. 1973. Pharmacological prevention of acute ventilatory capacity reduction in flax dust exposure. Brit. J. Industr. Med. 30: 381-384. 
10. HUME, R. \& E. WEYERS. 1973. Changes in leukocyte ascorbic acid during the common cold. Scot Med. J 18: 3-7.

11. HUME, R., E. WEYERS, T. ROWAN, D. S. REID \& W. S. HILLIS. 1972. Leukocyte ascorbic acid levels in acute myocardial infarction. Brit. Heart J. 34: 238243.

\section{DISCUSSION}

Ms. E. BARRETT: How often was ascorbic acid administered daily in both studies?

DR. COULEHAN: It was given as 1 gram every morning after breakfast.

Ms. BARRETT : What about 2 grams a day?

DR. COULEHAN: The 2 grams a day were not given in the second study. This dosage had been given according to the same schedule as in the first study, once a day and in tablets.

Ms. BARRETT: How did you get children under 10 years old to swallow four tablets in the morning?

DR. COULEHAN: We did not have much trouble. There were 944 children at the start of the second study and only 870 completed it, giving about an $8 \%$ dropout rate. Much of this was because of inability to consistently take the tablets. However, we did not find this to be a major problem simply because the kids liked the tablets and in fact, had very little difficulty swallowing them. These children take tablets all the time, as they are sick frequently with respiratory illness.

DR. R. MARTIN (Mount Sinai Graduate School, New York, N.Y.): You mentioned that the children with fewer colds had a higher blood level of vitamin $\mathrm{C}$ and those with more colds had a lower level, although the numbers were small. Is it possible that the number of colds affected the level and not the reverse?

DR. COULEHAN: We had two types of data. On one hand, we looked at all of the children who were identified as having had an episode of illness because they went to the clinic either by themselves or by referral. On the other, we also did systematic regular examination. In the case of the systematic observations it is obvious that our unit was limited to the day of observation and since that was every two weeks in a given child, we cannot relate these child-days of observation to episodes of illness. Consequently, a decrease in child-days of observation might represent fewer illnesses, but it might equally as well represent shorter illnesses. We were only able to correlate blood level data with the active surveillance or child-days of observation data. I think there were 30 days of illness in the one group and 55 in the other group. When you consider the possible days of observation in these children as well as the ratio of 30 to 55 days sick, it would seem the total number of days sick was not greater in either group.

DR. E. DEGKWITZ: If you give ascorbic acid once a day, at what time of the day do you measure the blood levels? Half-life time in males is about 6 to 12 hours, so the level would depend on the time of measurement.

DR. COULEHAN: It was impossible for us to give the tablets more than once a day. The blood ascorbate levels that were measured in the first study 
were determined 24 hours after the last tablets were administered. The second study included samples taken at various hours after the dose was given, but these results are not available.

DR. K. E. SCHAEFER (Naval Submarine Medical Research Laboratory, Groton, Conn.): Since you were doing some blood chemistry determinations, do you have any serological evidence as to the type of infectious agents you were dealing with?

DR. COULEHAN: We were unable to do serological studies and the results of ear and pharyngeal smear studies are not available. 


\title{
ANNALS OF THE NEW YORK ACADEMY OF SCIENCES
}

\author{
VOLUME 258
}

September 30, 1975

\section{SECOND CONFERENCE ON VITAMIN C *}

\author{
Editors and Conference Chairmen \\ C. G. KING AND J. J. BURNS
}

\section{CONTENTS}

\section{Part I. Metabolism of Ascorbic Acid}

Introduction: Overview of Ascorbic Acid Metabolism. By J. J. BURNS

Biosynthesis and Metabolism of Ascorbic Acid in Plants. By FRANK A. LOEWUS, GEORGE WAGNER, AND JOAN C. YANG

Synthesis and Some Major Functions of Vitamin C in Animals. By I. B. CHATTERJEE, A. K. MAJUMDER, B. K. NANDI, AND N. SUBRAMANIAN ... . 24 Chemistry and Metabolism of Ascorbic Acid and Ascorbate Sulfate. By B. M. TOLBERT, M. DOWNING, R. W. CARLSON, M. K. KNIGHT, AND E. M. BAKER 48 Liquid Chromatographic Analysis of Ascorbate and Ascorbate-2-Sulfate. By WILLIAM N. BIGLER AND DENNIS M. KELLY

Metabolism of Ascorbic Acid and Ascorbic-2-Sulfate in Man and the Subhuman Primate. By E. M. BAKER, J. E. HALVER, D. O. JOHNSEN, B. E. JOYCE, M. K. KNIGHT, AND B. M. TOLBERT

Utilization of Ascorbic Acid in Fish. By J. E. HALVER, R. R. SMITH, B. M. TOLBERT, AND E. M. BAKER.

Distribution of Ascorbic Acid, Metabolites and Analogues in Man and Animals. By DIETRICH HORNIG

* This series of papers is the result of the Second Conference on Vitamin C, sponsored by The New York Academy of Sciences and the Institute of Human Nutrition, College of Physicians and Surgeons, Columbia University, and held on October 9-12, 1974 in New York, New York. 
Part VI. Ascorbic Acid and Respiratory Illness

Large-Scale Trials of Vitamin C. By TERENCE W. ANDERSON

498

A Controlled Clinical Trial of Ascorbic Acid for the Common Cold. By THOMAS L. LEWIS, THOMAS R. KARLOWSKI, ALBERT Z. KAPIKIAN, JOHN M. LYNCH, GEORGE W. SHAFFER, DENNIS A. GEORGE, AND THOMAS C. CHALMERS

Vitamin $C$ and Upper Respiratory Illness in Navaho Children: Preliminary Observations (1974). By JOHN L. COULEHAN, Louis KAPNER, SUSAN EBERHARD, FLOYD H. TAYLOR, AND KENNETH D. ROGERS

Safety Considerations with High Ascorbic Acid Dosage. By LEWIS A. HARNESS 523

Ascorbic Acid Function and Metabolism During Colds. By C. W. M. WILSON 